\title{
Corruption and Structural Reforms in Cameroon
}

\author{
Pierre Rolland Atangana (Ph.D) \\ Industrial Economics, University of Yaoundé II- Soa, Cameroun \\ E-mail: pr_atangana@yahoo.fr
}

Received: March 7, 2012

Accepted: March 28, 2012

Online Published: August 16, 2012

doi:10.5430/rwe.v3n2p7

URL: http://dx.doi.org/10.5430/rwe.v3n2p7

\begin{abstract}
Inspired by the theory of conventions, a proposition is made of an application of the theory in the analysis and definition of government policies in Cameroon. The contributions of the conventional theory are highlighted and desirable government policies to confront the disorder proposed. The major results of our investigation consist of fighting corruption especially "political" corruption through an institutional framework rather than a using the principal-agent model.
\end{abstract}

Keywords: Corruption, Covention, Capture, Di-Patrimonialisation, Reforms

\section{Introduction}

The question of corruption nowadays constitutes a central object for the analyses of the appropriateness of reforms undertaken by African States at the beginning of the 90s. Most of these States were characterized by abyssal budget deficits and high levels of corruption (Note 1). These characteristics pushed experts and theorists to question the model of centralized management by the State.

Concerning the reduction of budget deficits, theory and practice reveal that competition through exerting a permanent pressure on the costs of services, which seems excessive in a monopoly regime, could become profitable in a competition regime, everything being equal. A classical contra-argument places doubt on scale effects, and underlined the low capacities of innovation of a monopoly and the possible perverse effects of public price systems. In addition, Shapiro and Willig (1990), Shleifer and Vishny (1993), and Boycko and al. (1996) whose works show that a non-benevolent government lead to corruption suggest that, the reduction of the role of the government in the direct operation of public utilities is relevant for curbing corruption.

Today, the criticisms that dominate all debates consider the extent of political corruption to be the major cause of the failure of the reforms (structural adjustment reforms) undertaken since the early 90s. Most studies showed that corruption worsens in the countries where: institutions are weak, the laws and the respect of regulation is not rigorously observed, the independence and the professionalism of the public sector lost their rigours, and the civil society lack the means to lead the government to exert pressure. All experts agree on the fact that corruption has a negative impact on development.

Generally, there are two forms of corruption: that of the agents, who take advantage of their position to enrich themselves at the detriment of the centre; that of the politicians who attain the behavior of the centre themselves, and the relationship between political power and voters. The first form of corruption does not pose specific problems a priori. It maybe resolved by using control mechanisms and penalties provided within the principal-agent framework (Note 2). Thus, the economic analysis of corruption of this type is similar to the economic analysis of crime (Ventelou, 2001) which presupposes the stability of the legal framework, power control and penalty for any malpractice. In this view, Banfield (1958), Rose-Ackerman (1978), and Klitgaard (1988) showed that in the presence of information asymmetry, the elimination of this form of corruption stumbles in the final analysis to the control cost of the subordinate.

The second type of corruption is political corruption (Ventelou, 2001) or systematic corruption (Kpundeh, 2001). It concerns government officials and is problematic since it involves the problem of controlling the controller (Laffont, 1997; Martimort and Bobbin, 1999). Hence, its integration into the economic analysis of crime is impossible. Political corruption or systematic corruption can become endemic as long as the legal framework (Note 3) continues 
to be redefined by corrupt politicians. In this case, many agents would be involved in the corrupted practice, leading to a very high social, political and economic cost. This type of corruption undermines confidence in political institutions and incites the disdain of the rule of law. It also distorts the allocation of resources and impedes market competition as well as affects in a fatal way investment, growth and development. The poorest classes of the population are the most affected since it forbids them the access to basic essential services.

The present article deals with political corruption, the political corruption that impacts negatively government policies and distorts all efforts of development. The study portrays the effects of political corruption and proposes measures (public policy) to curb it. Thus, as recommended by the reformers of the liberal school of thought, what is the concept corruption in an economic, political and social context like that of Cameroon? Can we admit the existence of a correlation between the political corruption and the quality of the institutional framework? What appropriate measures can be undertaken to assure an effective fight against political corruption?

In order to answer the above mentioned questions, we divide this study into two sections. The first section clarifies the concept of corruption. In the section, we expose the causes and the possible consequences of corruption using recent empirical and theoretical research on the subject matter. Next, the limits of the principal-agent (penalty-reward) model in the fight against political corruption are exposed and at the end, we draw inspiration from the theory of conventions (Note 4) to present an adequate institutional framework that seems fundamental for the controller to undergo voters' pressure.

\section{The Notion of Corruption}

Generally there are two forms of corruption: corruption of the subordinates qualified as "accessory" or "bureaucratic" and the "political" or "systematic" corruption. The various reforms, for example, budgetary restrictions and privatizations undertaken during the last two decades, did not reduce corruption but rather modify the actors involved and the forms of corruption.

\subsection{The Concept}

According to Shleifer and Vishny (1993) corruption is "the sale by government officials of government property for personal gain". Personal gain represents direct financial benefit accumulated by the government official or the politician. Thus, a corrupt act is any sort of abuse of power for private purposes; the abuse could be of a political, an economic or an administrative order. This definition does not include the purchase of public goods by the private sector, the cases where public goods are distributed to strengthen political support or when political choices are made to maximize the chances of re-election as forms of corruption. More absorbent definitions of corruption are stated by Bardhan (1997) who defines corruption as the "use of public offices for private gain" and UNDP ( 2004 ) which defines it as " the misuse of entrusted power for private gain, by means of bribery, extortion, trading of favours, nepotism, fraud, payments for facilitation or embezzlement".

\subsection{The Forms of Corruption}

The problem of corruption arises when an individual considers that the potential gain extracted by the act is worth the risk to be taken and to be sanctioned. Corruption often takes the form of a bribe (in Cameroon it is often called: Gumbo, beer, taxi, fuel, "tchoko", motivation) and it can equally be considered as theft or fraud. All sort of practices that involve the abuse of public power for private purposes are considered as acts of corruption. They include: the selective exemptions from customs duties, the attribution of import or export licenses in a non-competitive manner and the appointment of persons into certain positions on the basis of personal relations and not the merit.

Corruption has become an endemic problem that affects all aspects of existence. Generally, it is translated by a degradation of the state of law and a loss of legitimacy of the government. It distorts the normal usage of relations and involves an increased personalization of power. Under these conditions, political and bureaucratic dimensions of the problem are reinforced mutually and generate coalitions of lobbies which expropriate the wealth of the community.

Thus, in spite of its exceptional richness in natural endowment, the economic and social performances of Cameroon, which has a population of about 20 million inhabitants, is very low. In 2010, the growth rate of the country was only $3.2 \%$. The "Groupement inter-patronal du Cameroun (Gicam)" which is major employers' organization found that the economic performance of Cameroon was below the world average $(4.8 \%)$, African average $(5 \%)$ and the sub-regional average (4\%). Cameroon has risen twice in the Transparency International Corruption Perception Index as having very high level of corruption. Furthermore, the index of the perception of business climate, "Doing Business", ranks Cameroon the 168th on 183 countries in 2011. For the Global Competitiveness Index of Work Economic Forum (WEF), Cameroon is one of the least competitive States (111th on 133 countries). The incapacity 
of Cameroun to undertake the economic challenge is not due to a random or an unfavorable international economic situation (although it underwent significant external shocks) Rather, it is connected to the high level of corruption that remains a specificity of the country. In spite of international pressures and numerous plans or laws to fight against corruption, the practice remains a normal way of daily life. State employees at all level are corrupted. For example, to obtain promotions or to be transferred to other functions, the state employees must be "sponsored" or "helped" and it is often done at the entrance to the public service (Note 5).

In most of the developing countries, the causes of corruption are numerous and result from:

-an intense state intervention;

-numerous bureaucratic procedures;

- red-tape and gravities of the legal system;

-bureaucratic complexity arisen from multiple regulations and institutions for the fight against corruption (CONAC: National Commission for the Fight against Corruption; ARMP: Agency of Regulation of Procurement of contracts; National Observatory of Good Governance ....);

-administrative managerial limits; and

-the weakness of competitive pressure.

\subsection{Political or Systematic Corruption}

The corruption of the political milieu in diverse rankings is in the quasi-totality of the States of the globe. Like the other types of disfigured behaviors, corruption covers diverse practices that go from the purchase of political supports to the granting of favours and accessibilities to political allies. This type of corruption is connected to access to power and to the control and the exercise of this power. The phenomenon is however weak in economies that integrates politics in a democratic framework. This is because an elected corrupt official can be repudiated by his voters or lose support of his party and thus compromises his reputation.

Opened political systems, parliamentary debates on the policies followed and access to information by the citizens can contribute to subsume corruption by updating fraudulent practices. Cases of corruption of political arenas often reported in developed countries are signs of a smooth functioning of the institutions and systems put in place as they are able to expose such practices. The most common cases of political corruption concern:

- The financing of election campaigns;

- the attribution of procurement contracts on the basis of supports or of political memberships. Within the framework of the international transactions, corruption can also take the form of political pressures for the purchase of equipment or the attribution of markets or still, the manipulation of state capture in order to obtain gain (during reforms, multinationals have undertaken most state-owned enterprises);

- the contributions to election campaigns in the hope of drawing advantages later in the form of appointments or access to power;

- the use of a political office to take bribes and other illicit payments;

- the recourse to cronyism and clientelism as the basis of appointment into high office .

In spite of the considerable efforts to limit fraud, elections remain a domain in which the corruption of the political environment can show itself under explicit or implicit forms; and the offices and parliamentary privileges can easily be the object of abuse. The corruption of political milieus is detrimental on two bases: it concerns persons who exercise high responsibilities and it strengthens other forms of corruption.

These practices go from theft and fraud to the payment of bribes to obtain markets or information, by way of the additional payments, under-invoicing, collection of excessive commissions and payments to agents or intermediaries. These practices can also inflate artificially the amount of a market, supply goods and equipments of lower quality and charge un-rendered services.

Corruption can again exist in the context of government aid (Note 6) for development. Corruption that affects funds granted as development aid therefore weakens the utility of these funds and reduces the credibility of the government aid for development. 


\subsection{Bureaucratic Corruption}

This type of corruption is mostly present within the administration. It often occurs at the time of the privatization of public companies, implementation of projects of public works, attribution of public markets, payments of levies (taxes and custom duties...) or others, obtaining permits or licenses and bureaucratic and legal procedures.

It can also give room to theft, like whenever receipts and financial resources of the state are stolen, wages and commissions charged for work not completed, and taxes and legitimate rights obtained but not transmitted. Corruption can be punctual and non-organized, in the case of payments asked by state employees individually, or organized in a hierarchical manner. Like the other forms of corruption, it tends to perpetuates.

In many under-developed countries, rent-seeking by state employees is often the consequence of extremely low levels of salaries; and the problem is worsened by the compression of salaries scales and the limited possibilities of promotion. But corruption in the administration covers a set of more complex factors; and thus, many elements cancel the assumption of it coming to an end if the government sector increases without the implementation of certain measures. Furthermore, if poverty can explain partially the existence of small corruption and thefts, it could not excuse administrative corruption on a larger scale and higher levels. Insofar as measures are not taken to fight against this administrative corruption, there will be difficulty in reducing corruption at lower levels.

The most widespread form of corruption within administration is probably the appointment or the promotion of persons on the basis of relationship rather than merit. This phenomenon which is widespread in under-developed countries constitutes a factor of inefficiency because it is detrimental to the professionalism of the public service. But the most detrimental aspect is that the corruption perpetuates in the long-term and eventually anchors in institutions.

When the problem is generalized (corruption on a large scale where senior governmental officials accumulate enormous fortunes coexists within small corruption which sees the civil servant at all levels requiring to be made payment to carry out tasks or to provide services which enter within the normal framework their activities), the average individual ends up viewing this problem (with the wastage and the distortions that it involves) as an inevitable established fact. In the long run, a dysfunction of the public sector, a progressive inefficiency of the legal system and a loss of legitimacy of the State as an institution is attained. The degradation of the situation leads to an increasing proportion of administrative and economic activities entering the "informal" domain, thus contributing to widen the gap between the government and the individual.

The coexistence of the corruption of political arenas and that of the administration reinforced mutually and become more detrimental. It is generally the case in the countries which do not have strong countervailing forces at the level of institutions and a civil society, where the political, administration and private sector elites maintain very narrow links and where the control of public resources and the politics are inseparable.

\subsection{Corruption during the Processes of Political and Economic Transition}

Attention these years is driven to the process of political and economic transition, and corruption which they may engender as side effects. Presently, many developing countries are in a phase of transition. In the preceding systems, the problem of corruption relates to the government's extensive intervention in the economy and the regulation of public life. The negative effects of corruption were, without any doubt, among the factors which led (in the majority of cases) to the reforms. Democratic political systems and free economies are the best possibilities for controlling corruption. In periods of transition, corruption opportunities, especially when reforms are not well defined, could increase as a result of political liberalization.

Indeed the political and economic reforms can create conditions favorable for an increase in corruption. But in the long run, if they are applied effectively, they will favour a greater competition by establishing limits in the executive power and by encouraging the participation of the population in decision-making. In several economies, the uncertainties generated by a political and economic transition can be translated, in the short run, by an increase in corruption. On the whole, those who are threatened by the reforms can seek to maximize their advantages when they are capable of making it. Moreover, at the time when the old methods of control disappear without being replaced by new methods at the institutional level, the possibilities of rent-seeking and corruption can increase. Lastly, corruption can be more visible because of the reforms, the opening of the society in the political plan and the greater freedom gotten by the press and the organizations of the civil society creating new cases of corruption.

Besides, in the absence of transparent and responsible administrative systems and of the respect of law, corrupt individuals benefit from certain processes such as the privatization or the disengagement of the State. These processes can be manipulated to get advantages or privileged access to given groups. The experience of economies in transition reveals this and shows at which point it is important to attack the problems of governance at the first stages 
of the political and economic reforms. This positive evaluation contrasts the popular view among consumers and taxpayers in Cameroon, where, there is a wide perception that the poor are badly hurt by reforms and these reforms are perceived as forms of re-colonization.

In Cameroon, reformshave raised the level of bureaucratic complexity. Initially, one observes a high level of technical complexity of the provision of public services which has grown to rules that are not necessarily complied with and are politically disputed. These rules also allow numerous ways that can hide corruption operations. Then, bureaucratic procedures are lengthened. Leff (1964), Huntington (1968), Kaufmann and Wei (1999) noted that higher levels of corruption implies more time spent to treat with bureaucracy for companies.

Lastly, the time that it is necessary to quickly adapt to the procedures vary considerably. However, it is not unreasonable to assume that many procedures entail more bureaucratic complexity. Bureaucratic complexity can facilitate corruption in several ways and the problem is evident at all the stages of the statutory process: before the operation, in the form of the manipulation of the call for tender; during operation, for example, the opportunist renegotiation of the operational terms; or when the term of the operation comes to an end, without competition.

The complex procedures of signing documents offer opportunities to plead for certain aspects and so hide corruption. Thus, concerns about the protection of the national industrial development and marketing policy, and the question of employment and environmental protection can be exploited to hide a partial decision. The legitimization of the enterprise that proposes bribes or makes significant contributions finds its arguments. The audit and monitoring systems can therefore be exhaustive, but is not always for the detection of corruption. The bureaucratic excesses of hierarchy encourage the principal-agent problem rather than preventing the collusion between the agents and the firms. The continual proximity between bureaucratic hierarchy and the business environment and donor countries cause distortions in the signing of contracts.

"Accessory" corruption is the corruption carried out by the civil servant either by a violation of the procedures or by the passivity of the controller as if all the rules were complied with (for example, through the faking of offers or violation of rules of communication), or by the misuse of legitimate deviations of rules (for example, by referring to the discretionary decisions, extraordinary circumstances or preceding experiment). The possibilities of such a corruption are common when the number of procedures is increased (Fjeldstad, 2005; Moody-Stuart, 1997).

The second category of "political corruption" within this framework refers to the numerous ways that politicians influence bureaucratic procedures (for example, by giving instructions to the regulatory authorities on the way of establishing priorities for the call for tender or for factors that seem to support the political objective). It is admitted in literature that even if the nature of corruption differs between the benevolent government and the non-benevolent government, it is easy to hid or carry out crime in each circumstance if administrative rules are numerous. Gasmi et al. (2006) noted that, in developing countries, the positive effect of bureaucratic complexity on the performance of regulation is higher. Thus, performance in sectors like the electricity, water and telecommunications sectors is affected the by relationship between the level of corruption and the bureaucratic level of complexity.

Estache, Goicoechea, and Trujillo (2009) (Note 7) in a study on network companies find an improvement of wellbeing in the telecommications sector and none in the electricity and water sectors resulting partly from technological progress. Technological progress has increased competitive pressure. In the water and electricity sector, the low introduction of technological progress favours the capture of rents. In the water and energy sector there exists local competition at a small and average scale. Tondel and Soreide (2009) (Note 8) showed that performance depends on the policies that had been implemented by a country, particularly, its structure of governance, level of income, population and technological progress. They also conclude that the level of development of infrastructures is connoted positively by corruption. For Estache and Kouassi (2002) corruption increases the cost of water supply in African countries.

The ICRG (International Country Risk Guides) offers comparable figures for approximately 100 developing countries over a relatively long period. Defined as an evaluation of corruption within the political system, the index includes corruption such as bribes related to the trade, the taxes, or protection, but it concentrates on corruption in the form of excess of patronage, nepotism, reserved employment (favorable for favours), the financing of political parties, and the narrow link between politicians and businessmen. Between 1990 and 2005, ICRG reveals that the levels of corruption increased by $29 \%$ percent on overage in developing countries.

The problem of corruption is attributed to the intervention of the State in the economy since public intervention generates a significant volume of rents which are the subject to illegal securement by state employees. Micro-economic research on the causes of corruption is based on the contributions of the economics of information 
and agency models. But, the largest obstacle associated with the fight against corruption is due to the difficulties of measuring the phenomenon empirically since it is clandestine in nature. Many methodologies of the measurement of corruption are based on perception whose validity and fidelity are sometimes doubtful. An act of corruption, implying the negotiation between two agents on a certain agreement in a well defined institutional structure to carry out an unspecified transaction imposes an adaptation of an institutional framework, rather than a reinforcement of controls. This pushes us to admit that the problems of corruption should fall under the theory of conventions.

\section{The Contributions of the Theory of Conventions}

\subsection{The Contribution of the Agency Theory}

On the basis of the observation that all actors do not have the same stock of information during exchanges and that their action and effects of their actions are not easily observable and quantifiable (for example the realization of an electoral program, costs of construction of a hospital or a university), the economics of information and moral hazard studies the possibilities of behaviours deviating in markets and administrations. This research analyzes secondly measures that could reduce these deviating behaviours at lower cost.

Corruption is due to the opportunist behaviors of rational agents in the corruption market. There is a possibility of the phenomenon with the existence of a divergences of interests between agents and principal and for the simple fact that information asymmetry in favour of the agents leaves them a room for discretionary manoeuvre in their behaviors. This approach models the behavior of agents of the public sector (See Annex II, Figure 1). In the figure, the principal (P) creates rules which are applied by the agent (A). These are designed to regulate exchange with the customer (C). Such an exchange is related to the payment of taxes and tariffs levies, the supply of services and licenses, or the award of contracts. This framework is then employed to determine a system of optimal regulation, everything being equal. Conflict of interests exists between the principal and the agent; the principal is not informed about the effort employed by the agent on the application of these rules (the effort is not observable by the principal). The agent can hide information from the principal after the contract is negotiated. Thus, the principal is faced with the unfavourable adverse selection or moral hazard problem. A possible solution to resolve this problem of information asymmetry is for the principal to pay "an information rent" to the agent who reclaims afterwards the residual of the operation. This rent motivates the bureaucrat to reveal hidden information.

Another crucial characteristic of corruption can be seen in the relationship of the agents with the third party. A customer adds another dimension to the principal-agent approach. Corruption can take place when an agent breaks rules laid down by the director while getting along with the customer. The goal of a backhander is to separate the loyalty between the agent and the principal and to bring the agent who violates rules in favour of the customer. It is this type of complicity between the customer and the agent that creates corruption in the public sector.

Another variant of the principal - agent arises when a supervisor assigned to watch the agent and to bring back sincerely real information to the principal, can limit informative asymmetries sustained by the principal. But if a supervisor can get along with the agent, he can be motivated to distort his report. The distortion of the clauses of contracts is thus an effective consequence of the report of corrupt business.

Indeed, the supervisor, introduced to control the actions of the agent, could be corrupt too (see Annex II, Figure 2). The backhander contributes to the inefficiency of the public sector and increases the problems of informational asymmetries. The total level of corruption thus appears endogenous in the model, and varies with measures taken by the principal. The reduction of corruption is generally costly to be realize and undertaken. The costs can result from detection and punishment. Information asymmetry between public state employees and private agents associated with the multiplicity of rules and their frequent changes sometimes renders the control of acts of corruption impossible or very costly. This often leads to the collusion between agent (A) and supervisor (S/C) in order to extract and share rents.

The positive approach of the State admits explicitly that civil servants are rent seekers. They abuse their offices to maximize their own interests at the detriment of the general interest. This approach makes it possible to better understand the effective functioning of the public sector through the integration of the political and social factors in the economic analysis. It is from this renewed point of view that the theory of rent-seeking is developed. It is the logical product of the recognition of the permeability of the State to pressures of various natures. These pressures can be exerted by means of bribes given to the actors of the public sector. Corruption appears therefore as a particular form of rent-seeking.

The principal actor of the public sector is placed at the heart of the analysis and the economic effectiveness of public intervention is stressed. The rent-seeking theory builds itself on the intuition that, public intervention provides 
opportunities for the illegal securing of collective wealth. One can thus distinguish two levels of rent-seeking: in the "upstream" and in the "downstream" of public decision.

Upstream rent-seeking which we qualify as the search of primary rent aim at making it possible that a particular measure that has favourable distributional effects should be undertaken. Whereas, downstream rent-seeking also called secondary consists in trying to be among the beneficiaries of a given public action. The search for primary rent provokes state intervention, while the search for secondary pension results from it. The typical example of the search for primary rent is the one of a company which exerts pressure on public authorities to have a right of monopoly for its production (the institution of import quota or customs rates relates to the search for primary rent). Rent seekers (for example multinationals) have the means to exert pressure and so corruption constitutes a mode of the search of primary rent especially in developing countries. This is because of the problems of governance associated to the latter.

Corruption is also a means of search for secondary rent. A typical example of rent seeking induced by the existence of import quota studied by Krueger (1974) show that the detention of an import license gives the right to a part of the total rent generated by the quota system. Bribe payment to the state employees charged to attribute licenses can be a means of collecting the corresponding rent.

The paradigm of rent-seeking builds itself on a kind of law according to which, there is a rent, which is potential or effective, and there are individuals who would spend resources to try to get it. These expenditures for rent seeking have a negative social value in the sense that they constitute a wasting at the social point of view since they really induces a wasting of the available resources. They are therefore also harmful to growth (they are the expenditure of corruption in the form of bribe, which generates a dead loss for the company because of the wasting of the public resources available). The economy of conventions presents a common concept which is a concept that is at the same time broader and more demanding.

\subsection{Corruption: "Bad Convention"}

Corruption can be understood as a bilateral relation between the State which carries public policy and the interlocutors of the State, the public or the beneficiary voters of public policy (in an approach "economic analysis of the vote"). The stake is the implementation of various means by which general interest could be obtained and not the systematic exploitation for personal ends of a situation of a rent. For the purpose, conventions offer effective and simple solutions to these bilateral relations or coordination (p. Batifoulier, B. Ventelou; on 2003); which are in priori complexes. When each knows how the other one is going to behave, the problem with multiple solutions is converted into interrogation with a single and obvious outcome (when a taxi-man arrives at a police check, he knows that what awaits him, it is giving the "gombo" and not the file and the police officer also awaits this gesture which is commonly called ritual or traditional). Convention materializes this process of convergent anticipations and thus produces effective coordination.

The convention of coordination should not be seen only as one means of directing anticipations towards the realization of an objective desired by all and of success (Batifoulier and Ventelou, 2003). The concept of convention which returns to a state of balance should not be confused with optimality; coordination can be sub-optimal.

For a sub-optimal coordination, Batifoulier (2001), Larquier and Batifoulier, (2003) were the first to use the term "bad convention". Also, Batifoulier, Biencourt and Larquier (2003) provided a point of support to study the case of corruption in developing countries and thus extend to non-consensual situations, an area covered by the theory of conventions. Schelling and Weber the "founding fathers" of this theory underlined the harmful consequences of the continuous conventions (Note 9).

According to Schelling,: by what means can we obtain the general interest and not the private interest? Schelling (1960) mobilizes a framework of a game of "public interests" where the individuals adopt a "conflict strategy" (resulting from divergences of interest between the State and the voters) which leads to a situation of "limited war". For Schelling (1960) the conflict is a kind of context in which the participants try to gain. In this type of conflict situation, the parties can have interest in a "mutual accommodation". This means that a common interest cannot co-exist between the participants in conflict that appears in the form of a tacit bargaining. A typical example is a ticket of 1000 francs CFA established as a "pass right" between the road transporters and the police officer (each of them seeks for personal interest). As an illustration (see Annex I, table 2), let there be two players E (State) and I (interlocutors) and two possible strategies $X_{E / I}$ and $Y_{E / I}$. It is a static and symmetric game with imperfect and complete information. The game constitutes four strategies a, b, c, $\mathrm{d}$ for each player, where interaction appears in the form of a game of coordination having several equilibria. Formally, interaction appears as a game of coordination 
admitting several Nash equilibria (Note 10). If $a>c$ and $d>b$, two Nash equilibria arise. If $a=d$, the game is called a pure-coordination game since the equilibria are Pareto equivalent. If $a \neq d$ we have a game of classic coordination called a "rendez-vous game" or still "game in Schelling" with a Pareto dominant equilibrium A (if a $>d$ ). Adding to the game the condition $(\mathrm{a}-\mathrm{c})<(\mathrm{d}-\mathrm{b})$, a game of the type "Stag Hunt" is obtained. Thus, D "risk dominates", a terminology introduced by Harsanyi and Selten (1988).

The moralizer thus has a difficulty in explaining the selection of equilibrium in the game of coordination using conventional tools. The real actor is confronted with only a few difficulties in making his decision. The conjunction of these two characteristics (complicated theoretical explanation but easy real decision) leads to the mobilization of the notion of convention. It is indeed by convention that the actors make their decision. Each adopts a behavior that he believes that the other one is going to adopt and the convention coordinates their anticipations by suspending deliberation (Batifoulier and Ventelou, 2003). Only preference for conformity is a guide to their action (Lewis, 1969). The selection of equilibrium is then made on an implicit and arbitrary base (in the case where several solutions are possible). The notion of convention enables a solution to be obtained to the problem of multiple equilibria in game of coordination. Defined as the set of strategies played in the Nash equilibrium, it is a stable solution, coming from the past and auto-reinforcing (Batifoulier and Ventelou, 2003).

But since this solution is arbitrary, it is not inevitably optimal. The existence of coordination being more significant than its quality, it is always possible that the rational players agree on a Pareto dominant solution. They can thus adopt a "bad convention" which is nothing else than a defect of coordination (Larquier and Batifoulier, 2003), a state where an economy is settled in a Pareto dominant equilibrium for a long time (Cooper and John, 1988).

It is thus possible to have rational individuals agreeing on a solution for which they are aware that it is detrimental for them (the taximan and the police officer). This blocked situation remains in spite its sub-optimality because each anticipates the sub-optimal behavior of the others and holds it for an asset. Thus, they seem not to have other alternatives. This situation qualified as a "trap in convention" (Ventelou, 2003) gives birth to an unfavourable configuration which seems to be more difficult to escape from, but which the individuals are not necessarily aware of being in the situation.

The concept of defect of coordination could correspond to that of "failure of government"; it describes a situation where a side of the public sector settles conventionally in a negative attitude whereas another configuration within it is reached. It then translates a situation of wastage, additional costs, commodification (free transfer to those who pay), accounted in theory of bureaucracy or agency theory. It can be said that the inefficiencies of the public sector are not imputed in this case to human nature which would develop in all circumstances the spirit of enrichment in the context in which public policy develops. The concept of the "trapdoor of convention" (Batifoulier and Ventelou; 2003) suggests the idea of inefficiency of the public sector corresponding to a defect of coordination which nourishes itself. It appears to individuals as a natural force which nobody can break off from it. The concept of convention enables the study of the idea of the "naturalization" of certain situations of public inefficiency. Nevertheless, these situations are not immutable since another solution exists.

Indeed, the concept of convention describes the existence of a system of mutual expectations. The way in which each represents the other dictates the action to be taken. Each one anticipates the behavior of the other according to what it thinks of being the behavior appropriate in such situation vis-a-vis such partner. One acts differently according to whether one deals with opportunist or philanthropist. The stabilization of this set of cross anticipations materializes in a convention. However, as we had explained, these conventions can lead to negative and blocked situations. It is the case when the State perceives its agents as animated by the search of the least effort, opportunism or by the valorization of an excessive wastage. The centre then develops a system of regulation which makes beautiful share to financial rewards. The "strategy of carrot" must bring the individuals to honesty since they have interest in it from thenceforth. But on other side, the interlocutors of the State expect a suspicious State, developing logics of bonus surcharge. They act as accordingly: commercial logics and competition, the strategies of shirking, etc overriding those of general interest.

One is locked up then in a sub-optimal equilibrium, detrimental to some as to others. The interlocutors of the State are not as opportunist as the theory of the incentives claims (which states that, only an incentive contract would reoriented deviating agents by compensating them for the loss of utility undergone); and the "venal", interested and opportunist behaviour appears to be more endogenous than exogenous (as also assumed by the principal-agent relation). The individuals can be animated by not only extrinsic motivations but also intrinsic motivations (Kreps, 1997; Benabou and Tirole, 2003). There are undoubtedly conflicts of interest between the State and its interlocutors. 
How to Capture and Measure Dysfunctions in a Developing country? The various empirical studies on corruption failed largely on the legal stumbling block. In Cameroon, the phenomenon is easily located by the number of businesses treated by courts. Very few businesses are treated and sanctioned. If corruption remains limited within a relatively solid legal framework, control by the center is possible. Beyond a threshold, the unit can collapse jointly to create a "trapdoor for corruption" where dysfunctions accumulate. The "politico-economic" model presented (on the diagram hereafter) takes as a starting point to this reflection and tries to reproduce a structure of defects of coordination for corruption and its effects.

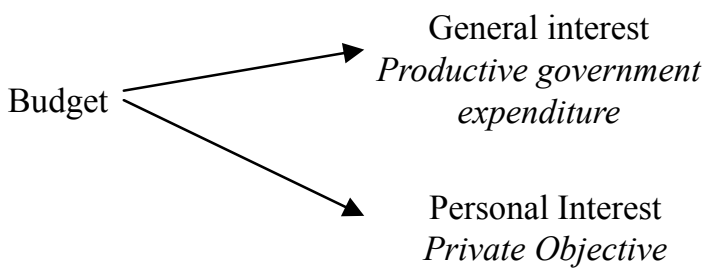

The government has two choices: to impose without delay its personal interests, or, to differ and invest in productive government expenditure. This choice is guided by the political lifespan of the government. A government enjoying a long horizon of maintaining power will tend to maintain the national economy i.e., will choose general interest since it is the means through which it satisfies its personal interests. On the contrary, in the case of a short political lifespan, the politician is placed in an unstable situation, it can only benefit from the opportunity of the brief period offered to it to misuse the funds that it controls. It therefore takes away some funds immediately and sometimes appropriates all funds (it is the case of the developing countries). Corruption becomes in this case an extreme form of predation (a large-scale appropriation of funds, operated in the urgency). Thus, a government subjected to a high political instability is characterized by a form of extreme predation and, a government profiting from stability meets "the general interest". On the whole, the amount of predations appears in a decreasing relationship with the time horizon of the governments and corruption being the extreme case.

The voters, in their majority, benefit from government policy when it is effective, i.e. when it results to productive expenditure. In this simple "model", the voters are thus predominantly penalized by the predations (personal interests). They in turn sanctions those who diverge politically (more predation, less political support, less chance to remain with the capacity). Technically two situations of equilibrium appear: the first equilibrium situation is that in which corruption appears, the politicians briefly pass to power, and divert public funds. This policy is radically sanctioned by the agents. The second situation is that in which predations remain limited, the voters rewards this morality and, at the same time, provides to the government a sufficiently long lifespan to justify a tightened deduction. It is obvious that this second configuration is socially desirable. This is illustrated on table 3 (annex I). Both equilibria are Pareto ordered. They can be qualified as high equilibrium and low equilibrium. The first one Pareto-optimal equilibrium (A) which results from the general interest policy strategy by the government and re-election strategy by voters corresponds to the absence of corruption. The second (D) resulting from personal interest strategy by government and vote sanctioned strategy by voters is a "corruption, political instability" trapdoor corresponding to a defect of coordination.

Since the solutions of the game are Nash equilibria, the defect of coordination is stable. In other words, corruption can settle down on a long-term basis, and it is the same if it is not carried by the same corrupted individuals. The voters by sanctioning the dishonest political decision makers do not end the conventional practice of corruption. Such a defect of coordination can be interpreted as a "bad convention". The term "bad" here is equivalent to the expression "sub-optimal"; one also talks about "arbitrary". To define the equilibrium D as sub-optimal, it is to recognize that the state of corruption is harmful to the community; this assertion concerns the common conception. It should be noted that this state is unfavourable to the various actors. It is costly to the government whose lifespan is prejudiced and to voters whose work and production are diverted.

A state of corruption can thus be considered as a consequence of a bad convention and not as a cause of dysfunction. Corruption then does not result only from one dictatorial behavior where the corrupted substitutes its interest for the general interest but a behavior which is due to what is practiced in the surrounding environment. Thus, one can associate corruption to a moral prohibition which nevertheless let itself to be a venal behavior. Corruption is seen here like a conformism. The utilitarian theory of conventions makes of this conformism a rational and long-lasting behavior, but is potentially sub-optimal; qualifying it "bad convention". It translates a collective inefficiency. 
The stag hunt game, which constitutes the archetype game of this approach, explains this. This type of game is able to show that the Pareto dominated solution are attractive and so, the players can legitimately adhere to it. Each of the two equilibria is "good" according to the privileged criterion; there is a real indifference between the branches of the alternative. But utilitarian calculation raises indecision by defining convention followed as that which makes it possible for the risk incurred from the change of strategy to be minimized. Thus, in risk predominance, the high equilibrium of the game of coordination seems dangerous. This leads to the adoption of rather the cautious equilibrium. It is thus rational for at least one of the players to adopt the sub-optimal solution. For this credible eventuality, it is up to each player to integrate a non-null probability that the other does not choose the Pareto-optimal outcome, even if each thinks that it is better to choose Pareto optimality. Equilibrium D, enables the formalization of the problem away from an institutionalization of the political relationship. It is difficult to control of "political corruption" within a theoretical framework, that of non-cooperative games.

Weber (1971) puts forward the idea of reinforcing the institutional dimension of the analysis, and makes a distinction between the "legal-rational" mode and the "traditional" mode. The "traditional" mode and one of its sub-types, the "heritage" mode enables us to describe a precise form of power in developing countries. It is characterized by confusion between government resources and the private laws of the leaders. . If this confusion permits the existence of a class of leaders with important public power, it is a source of the dysfunction regarding the modern criteria of administration. The leader uses and misuses government property, confusing his personal wealth with national heritage. Thus, corruption is likely and frequent in this type of system.

The game of coordination described above enables one to characterize the institutionalization of two Weberian modes. The "rational legal" mode is high equilibrium and good convention, the "patrimonial" mode is low equilibrium and bad convention (see Table 4, annex I for illustration). Developed countries have for this proceeded with the "di-patrimonialisation" of public funds and to seek general interest. In a patrimonial mode which configures a personal interest policy government strategy and mistrust by voters and instability corruption appears natural. This is the case in Cameroon. Not involving in the act appears sometimes unbelievable. These attitudes are very difficult to destabilize since they appear conventional. Thus, corruption appears as a natural force that cannot be broken. This gives rise to its restrictive character. A convention even if judged negatively can perpetuate for a long time.

While the rational legal model joins the "civic city" (which develops general interest), the patrimonial mode joins the "domestic city" (which develops the bonds of proximity). Within the framework of the "domestic justification", it is a question of judging in conformity or legitimately the primacy given to close relations, to parents, to the neighbors.... In certain configurations, like those associated to the family circle, this design concerns common expectations and each one expects that the others act on the same conventional register. The analyzed corruption under this view take on certain legitimacy at the point where the convention that underlies it cannot be described any more as "sub-optimal" if it is considered that all the registers of justification are on the same plan.

\section{Conclusion}

Finally, the method of evaluating the theory of conventions has enabled a good evaluation of the concept of corruption. For the case of Cameroun, the major lesson drawn lies in the need to implement an adequate institutional framework; most empirical studies based on the principal-agent model show their limits and subjectivity in the criteria selected. This institutionalization will permit the "di-patrimonialisation" and the search for general interest satisfaction to enable Cameroon to reach a "civic city".

\section{References}

BANFIELD, E. (1958). The Moral Basis of a Backward Society. Free Press, New York.

BARDHAN, P (1997). Corruption and Development: A Review of Issues. Journal of Economic Literature ,(35), 1320-1346.

BARRO, R. (1990). Government Spending in a Simple Model of Endogenous Growth. Journal of Political Economy, (98), 103-125.

BATIFOULIER P. (éd.) (2001). Théorie des conventions. Economica.

BATIFOULIER P., BIENCOURT O., \& LARQUIER G. (2003). L'Économie des conventions et les théories des conventions. Communication au séminaire Economie et Institutions. Université Paris-X-Nanterre, 24 avril, document de travail Forum 2003-2.

BAYART J.F. (1989). L'Etat en Afrique, la Politique du Ventre. Fayart, Paris. 
BENNABIB, J., \& A. RUSTICHINI (1996). Social Conflict and Growth. Journal of Economic Growth, (1), $125-142$.

CADOT, O. (1987). Corruption as a Gamble. Journal of Public Economies, (33), 223-244.

DEVARADJAN, S., V. SWAROOP, \& H.F. Zou. (1996). The Composition of Public Expenditure and Economie Growth. Journal of Monetary Economies, (37), 313-144.

KLITGAARD, R. (1988). Controlling Corruption. University of Columbia Press.

LAFFONT, JJ. (1997). Économie Publique et Information. Économie et Prévision, international d'économie publique appliquée.

MARTIMORT, D., \& J.C. ROCHET. (1999). Le partage public-privé dans le financement de l'économie. Revue Française d'Économie, (XIV), 33-77.

MAURO, P. (1995). Corruption and Growth. Quarterly Journal of Economies, (110), 681-712.

ROSE-ACKERMAN, S. (1978). Corruption: A Study in Political Economy. Académie Press.

SCHELLING T. C. (1978). Micromotives and Macrobehavior. WW Norton \& Company.

SCHELLING T.C. (1960). The strategic of conflict. Harvard University Press.

SCHLEIFER, A., \& R. VISHNY. (1993). Corruption. Quarterly Journal of Economies, (CIX), 599-617.

THEOBALD R. (1990). Corruption, Development and Underdevelopment. MacMillan, London.

TIROLE, J. (1996). A Theory of Collective Reputations with Applications to the Persistence of Corruption and to Firm Quality. Review of Economie Studies, 63(1), 1-22.

VENTELOU B. (2003). La corruption dans un modèle de croissance. Revue d'Economie.

WEBER M. (1971). (ed. fr.), Economie et Société. Plon, Paris.

\section{Notes}

Note 1. The reformers promise an efficiency in the access and supply of basic services and other social advantages.

Note 2. It consist of the principal obtaining the full realization of his mission from the agent what so ever the acts that is observed.

Note 3. Insofar as the legal framework can be redefined by the corrupted politician, this type of corruption engages the individuals as much as the systems and, consequently, the whole of control and legal sanction institutions.

Note 4. The failure of the empirical methods to evaluate corruption and the subjectivity of the concept of index of perception which the majority uses gives us the room to apprehend corruption in the light of the theory of conventions. It apprehends corruption as the unhappy exit of a problem of coordination "bad convention" and of which the resolution deserves a more adequate institutional framework where the controller must undergo voters' pressure.

Note 5. The "godfather" then waits for recognition from the civil servant, which is not only verbal.

Note 6. Generally, this form covers with the irregularities of management or the embezzlements which are not detected because of the absence of adapted methods of control and of the lack of respect of measurements aimed at promoting responsibility and the transparency. It can lead to bad implementation of projects of development, non-reachability of funds or products to potential beneficiaries and services are not assured. In certain cases, the provisions of development aid continues even when it is obvious that the funds were diverted or badly managed, and in extreme cases, international assistance makes it possible to corrupted political leaders to remain in office after their legitimacy ends.

Note 7. Antonio Estache, Ana Goicoecha, Lourdes Trujillo; "Utilities reforms and corruption in developing countries"; Utilities Policy, 2009

Note 8. Line Tondel Seim, Tina Soreide; "Bureaucratic complexity and impacts of corruption in utilities"; Utility Polic; 2009.

Note 9. Schelling for the approaches related to the game theory and Weber for the one close to the economics of conventions.

Note 10. The Nash equilibrium is one of the concepts most used in game theory application to the economy, when it is the question of studying interdependent behaviors of agents having contradictory objectives. The example of a 
game of the battle of sexes corresponds to a case of a finite set of strategies. It models a conflict between Antoine and Marie, who have each a choice between buying a ticket for a concert of rock'n'roll (R) or a football match (F).Marie prefers the concert whereas Antoine prefers the football match but they prefer to be together rather than separating. The normal form of this play is represented by the following matrix, Marie choosing a column and Antoine a row.

Table 1. Correlation between corruption, bureaucratic complexity and return (Estache, Goicoechea, and Trujillo, 2009)

\begin{tabular}{|c|c|c|c|}
\hline Categories & $\begin{array}{c}\text { Number of } \\
\text { countries }\end{array}$ & High return & $\begin{array}{c}\text { Low } \\
\text { return }\end{array}$ \\
\hline $\begin{array}{l}\text { Less corruption and } \\
\text { less complexity }\end{array}$ & 26 & 20 & 6 \\
\hline $\begin{array}{l}\text { Less corruption and } \\
\text { more complexity }\end{array}$ & 16 & 9 & 7 \\
\hline $\begin{array}{l}\text { More corruption and } \\
\text { less complexity }\end{array}$ & 15 & 3 & 12 \\
\hline $\begin{array}{l}\text { More corruption and } \\
\text { more complexity }\end{array}$ & 27 & 10 & 17 \\
\hline
\end{tabular}

Table 2. The matrix of the gains in a generic $2 \times 2$ game

\begin{tabular}{|c|c|c|c|}
\hline & \multicolumn{2}{|c|}{ Interlocutors } \\
\hline & & $X_{F}$ & $Y_{F}$ \\
\hline \multirow{2}{*}{ State } & $X_{E}$ & $(\mathrm{a}, \mathrm{a})$ & $(b, c)$ \\
\hline & $Y_{E}$ & $\begin{array}{c}(\mathrm{c}, \mathrm{b}) \\
\mathrm{C}\end{array}$ & $\begin{array}{r}(\mathrm{d}, \mathrm{d}) \\
\mathrm{D}\end{array}$ \\
\hline
\end{tabular}

Table 3 ( 2 bis). Matrix of gains in a game applied to corruption (2X2)

\begin{tabular}{|c|c|c|c|}
\cline { 3 - 4 } \multicolumn{2}{c|}{} & \multicolumn{2}{c|}{ Voters } \\
\cline { 3 - 4 } \multicolumn{2}{c|}{} & $\begin{array}{c}\text { Re-election } \\
\mathrm{R}\end{array}$ & $\begin{array}{c}\text { Vote sanctioned } \\
\text { VS }\end{array}$ \\
\hline \multirow{3}{*}{ Government } & $\begin{array}{c}\text { General interest } \\
\text { Policy }\end{array}$ & $(\mathrm{a}, \mathrm{a})$ & $(\mathrm{b}, \mathrm{c})$ \\
& $\mathrm{A}$ & $\mathrm{B}$ \\
\cline { 2 - 4 } & Personal interest & $(\mathrm{c}, \mathrm{b})$ & $(\mathrm{d}, \mathrm{d})$ \\
& & $\mathrm{C}$ & $\mathrm{D}$ \\
\hline
\end{tabular}

Table 4. Conventions and corruption level

\begin{tabular}{|c|c|c|c|}
\cline { 3 - 3 } \multicolumn{2}{c|}{} & \multicolumn{2}{c|}{ Voters } \\
\cline { 3 - 4 } \multicolumn{2}{c|}{} & $\begin{array}{c}\text { Long-lasting confidence } \\
\text { Stability }\end{array}$ & $\begin{array}{c}\text { Mistrust } \\
\text { Instability }\end{array}$ \\
\hline $\begin{array}{c}\text { Admisnistrative } \\
\text { hierachy (rulers) }\end{array}$ & $\begin{array}{c}\text { General interest } \\
\text { policy }\end{array}$ & $\begin{array}{c}\text { Rational legal mode } \\
\text { Civility }\end{array}$ & $\begin{array}{c}\text { Non-viable } \\
\text { configuration }\end{array}$ \\
\cline { 2 - 4 } & $\begin{array}{c}\text { Personal interest } \\
\text { policy }\end{array}$ & $\begin{array}{c}\text { Non-viable } \\
\text { configuration }\end{array}$ & patrimonial mode \\
\hline
\end{tabular}




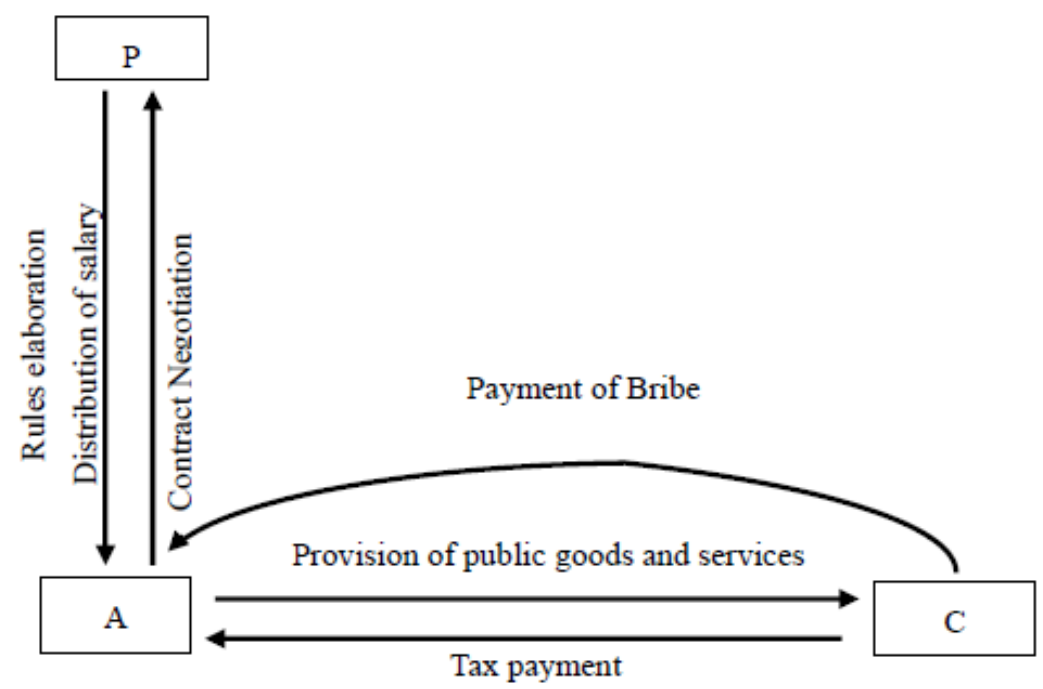

Figure 1. The Phenomenon of Corruption according to the Principal-Agent-Customer model

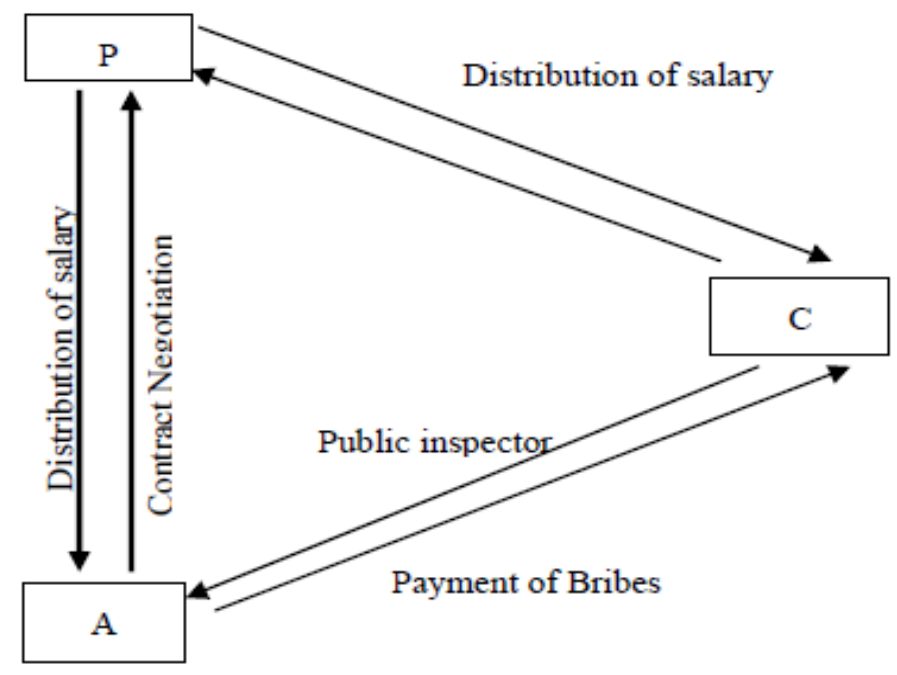

Figure 2. The Principal-Agent-Supervisor model (Gref Lamsdroff, 2001) 